Tropical Journal of Pharmaceutical Research April 2010; 9 (2): 141-148

(C) Pharmacotherapy Group,

Faculty of Pharmacy, University of Benin

Benin City, 300001 Nigeria.

All rights reserved.

Research Article

Available online at http://www.tjpr.org

\title{
Antioxidant Activity of the Bulb and Aerial Parts of Ornithogalum sintenisii L (Liliaceae) at Flowering Stage
}

\author{
Mohammad Ali Ebrahimzadeh ${ }^{1 *}$, Seyed Mohammad Nabavi ${ }^{1,2}$, \\ Seyed Fazel Nabavi ${ }^{1}$ and Bahman Eslami ${ }^{3}$ \\ ${ }^{1}$ Pharmaceutical Sciences Research Center, School of Pharmacy, Mazandaran University of Medical Sciences, \\ 48189, Sari, ${ }^{2}$ Department of Biology, University of Mazandaran, Babolsar, ${ }^{3}$ Department of Biology, Islamic Azad \\ University, Ghaemshahr Branch, Iran.
}

\begin{abstract}
Purpose: Ornithogalum sintenisii is an Iranian species with little known about its pharmacological effects. The purpose of the present study was to investigate some antioxidant properties of the plant.

Methods: The antioxidant potency of the freeze-dried methanol extract of $O$. sintenisii bulbs and aerial parts were investigated by evaluating the following parameters: linoleic acid peroxidation, 1,1-diphenyl2-picryl hydrazyl radical (DPPH), scavenging of nitric oxide and hydrogen peroxide as well as reducing power and $\mathrm{Fe}^{2+}$ chelating activity, using standard methods. Phenol and flavonoid contents were determined as gallic acid and quercetin equivalents, respectively.

Results: The aerial parts contained higher phenol and flavonoid contents than the bulbs. $I C_{50}$ for DPPH radical-scavenging activity was $368 \pm 15$ and $669 \pm 25 \mu \mathrm{g} \mathrm{m} \Gamma^{1}$ for aerial parts and bulbs, respectively. The reducing power of the extracts was less than that of vitamin $C(p<0.01)$ with the aerial parts showing stronger activity than the bulbs $(p<0.01)$. The extracts did not show any activity in the peroxidation test but displayed good $\mathrm{H}_{2} \mathrm{O}_{2}$ radical scavenging activity compared with quercetin $\left(\mathrm{IC}_{50}=\right.$ $52.0 \pm 3.1 \mu \mathrm{g} \mathrm{m}^{1}$ ) which was used as positive control.

Conclusion: The bulb and aerial parts of $O$. sintenisii aerial parts (at flowering stage) exhibited good but varying levels of antioxidant activities in nearly all the models studied.
\end{abstract}

Keywords: Ornithogalum sintenisii ; Bulbs; Aerial parts; Antioxidant activity; Flavoniods; Phenols.

*Corresponding author: E-mail: zadeh20@yahoo.com; Tel: +98-151-3543081-3; Fax: +98-151-3543084 


\section{INTRODUCTION}

Living tissues that derive energy from aerobic metabolism are under constant threat of damage by reactive oxygen derivatives. Such free radicals are usually short-lived species but they possess a single unpaired electron, rendering them highly reactive against biologically important macromolecules including DNA, proteins and membrane lipids.[1] To counteract this threat to their integrity, cells have evolved a variety of defense systems based on both watersoluble and lipid-soluble antioxidant species, and on antioxidant enzymes.[1] A high proportion of the antioxidant systems of the human body are dependent on dietary constituents [1]. Consequently, the search for natural antioxidants, especially of plant origin, has notably increased in recent years [2]. Ornithogalum sintenisii is an Iranian species of the genus Ornithogalum L. (Liliaceae) that encompasses well over 150 perennial bulbous species, mostly distributed in the temperate regions of Europe, Asia, and Africa $[3,4]$. To the best of our knowledge, no biological and phytochemical investigation has been carried out on $O$. sintenisii. However, previous studies on some other Ornithogalum species revealed the presence of steroidal glycosides [4,5], monoterpene lactone [6] and homoisoflavanone [7], some of which were found to possess antimicrobial, cytotoxic, cytostatic, anticancer, antioxidant, mould-inhibiting and insect deterrent properties $[4,8]$. The objective of this study was to determine some antioxidant properties of $O$. sintenisii bulbs and aerial parts using a set of in vitro antioxidant assays including scavenging of DPPH, nitric oxide and hydrogen peroxide, as well as reducing power, linoleic acid peroxidation test and iron ion chelating power.

\section{EXPERIMENTAL}

\section{Chemicals}

Ferrozine, linoleic acid, trichloroacetic acid (TCA), 1,1-diphenyl-2-picryl hydrazyl radical
(DPPH), and potassium ferricyanide were purchased from Sigma Chemicals Co., USA. Gallic acid, quercetin, butylated hydroxylanisole (BHA), ascorbic acid, sulfanilamide, $\mathrm{N}$-(1-naphthyl) ethylenediamine dihydrochloride, ethylenediamine tetraacetic acid. EDTA and ferric chloride were purchased from Merck (Germany). All other chemicals were of analytical grade or purer.

\section{Plant Material}

The bulb and aerial part (flowering stage) of O. sintenisii were collected from Khazar abad area (Panbeh chooleh, north of Sari, Iran) and identified by $\mathrm{Dr}$ Bahman Eslami (Department of Biology, Islamic Azad University of Qhaemshahr, Iran). A voucher (no NS76-NS79) has been deposited in the Sari School of Pharmacy Herbarium. The materials were dried at room temperature and coarsely ground before extraction. Each part $(100 \mathrm{~g})$ was extracted by percolation method using methanol $(400 \mathrm{ml})$ for $24 \mathrm{~h}$ at room temperature. The extract was then separated from the sample residue by filtration through Whatman No 1 filter paper. This procedure was repeated thrice. The resultant extract was concentrated in a rotary evaporator until a crude solid extract was obtained, which was then freeze-dried for complete solvent removal. Yields were 10.5 and $8.2 \%$ for bulb and aerial part, respectively.

\section{Determination of total phenolic and flavonoid contents}

Total phenolic contents were determined by the Folin-Ciocalteau reagent method [9]. The extract samples $(0.5 \mathrm{ml})$ were mixed with 2.5 $\mathrm{ml}$ of $0.2 \mathrm{~N}$ Folin-Ciocalteau reagent for $5 \mathrm{~min}$ and $2.0 \mathrm{ml}$ of $75 \mathrm{~g} / \mathrm{l}$ sodium carbonate was then added. The absorbance of the reaction mixture was measured at $760 \mathrm{~nm}$ after $2 \mathrm{~h}$ of incubation at room temperature. The results were expressed as Gallic acid equivalents. Total flavonoids were estimated using the method of Ebrahimzadeh et al [10]. Briefly, $0.5 \mathrm{ml}$ of each plant extract in methanol was 
separately mixed with $1.5 \mathrm{ml}$ of methanol, 0.1 $\mathrm{ml}$ of $10 \%$ aluminum chloride, $0.1 \mathrm{ml}$ of $1 \mathrm{M}$ potassium acetate and $2.8 \mathrm{ml}$ of distilled water, and left at room temperature for 30 $\min$. The absorbance of the reaction mixture was measured at $415 \mathrm{~nm}$ with a double beam spectrophotometer (Perkin Elmer). Total flavonoid contents were calculated as quercetin from a calibration curve.

\section{DPPH radical-scavenging activity}

DPPH radical was used for determination of free radical-scavenging activity of the extracts as previously described [11]. Different concentrations of each extract were added, in equal volume, to the methanolic solution of DPPH $(100 \mu \mathrm{M})$. The mixture was left for 15 min at room temperature and the absorbance was read at $517 \mathrm{~nm}$. The experiment was repeated three times, using vitamin $\mathrm{C}, \mathrm{BHA}$ and quercetin were used as standard controls. The results were calculated as $I_{50}$ values, which denotes the concentration of sample required to scavenge $50 \%$ of $\mathrm{DPPH}$ free radicals.

\section{Reducing power determination}

The reducing power of the extracts was determined according to the method of Nabavi et al $[12,13]$. Different amounts of each extracts $\left(25-800 \mu \mathrm{g} \mathrm{ml}^{-1}\right)$ in water were mixed with phosphate buffer $(2.5 \mathrm{ml}, 0.2 \mathrm{M}$, $\mathrm{pH}$ 6.6) and potassium ferricyanide, $\mathrm{K}_{3} \mathrm{Fe}$ $(\mathrm{CN})_{6}, \quad(2.5 \mathrm{ml}, 1 \%)$. The mixture was incubated at $50{ }^{\circ} \mathrm{C}$ for $20 \mathrm{~min}$. A portion (2.5 $\mathrm{ml}$ ) of $10 \%$ trichloroacetic acid (10\%) was added to the mixture to stop the reaction followed by centrifugation at $3000 \mathrm{rpm}$ for 10 $\min$. The upper layer of the solution $(2.5 \mathrm{ml})$ was mixed with distilled water $(2.5 \mathrm{ml})$ and $\mathrm{FeCl}_{3}(0.5 \mathrm{ml}, 0.1 \%)$, and the absorbance was measured at $700 \mathrm{~nm}$. Increased absorbance of the reaction mixture indicated increased reducing power. Vitamin $\mathrm{C}$ was used as positive control.

\section{Assay of nitric oxide-scavenging activity}

The procedure is based on the principle that sodium nitroprusside in aqueous solution at physiological $\mathrm{pH}$ spontaneously generates nitric oxide which interacts with oxygen to produce nitrite ions that can be estimated using Griess reagent [1]. Scavengers of nitric oxide compete with oxygen, leading to reduced production of nitrite ions. For the experiment, sodium nitroprusside $(10 \mathrm{mM})$, in phosphate-buffered saline, was mixed with different concentrations of each extracts dissolved in water and incubated at room temperature for $150 \mathrm{~min}$. Following the incubation period, $0.5 \mathrm{ml}$ of Griess reagent was added. The absorbance of the chromophore formed was read at $546 \mathrm{~nm}$. Quercetin was used as positive control [14].

\section{Metal chelating activity}

The chelation of ferrous ions by the extracts was estimated colorimetrically as described previously $[15,16]$. Briefly, the extract $(0.2$ $3.2 \mathrm{mg} / \mathrm{ml}$ ) was added to a solution of $2 \mathrm{mM}$ $\mathrm{FeCl}_{2}(0.05 \mathrm{ml})$. The reaction was initiated by the addition of $0.2 \mathrm{ml}$ of $5 \mathrm{mM}$ ferrozine; the mixture was shaken vigorously and left standing at room temperature for $10 \mathrm{~min}$. The absorbance of the solution was then read at $562 \mathrm{~nm}$. Percent inhibition of ferrozine- $\mathrm{Fe}^{2+}$ complex formation was calculated as $\left(A_{0}\right.$ $\left.A_{s}\right) / A_{s} \times 100$, where $A_{0}$ was the absorbance of the control, and $A_{s}$ the absorbance of the extract/standard. $\mathrm{Na}_{2}$ EDTA was used as positive control.

\section{Determination of antioxidant activity}

The inhibitory capacity of extracts against oxidation of linoleic acid measured colorimetrically as previously described $[10,17]$. Twenty $\mathrm{mg} / \mathrm{mL}$ of samples, dissolved in $4 \mathrm{~mL}$ of $95 \%$ ethanol, were mixed with 4.1 $\mathrm{mL}$ of $2.51 \% \mathrm{v} / \mathrm{v}$ linoleic acid in $99.5 \%$ ethanol, $8 \mathrm{~mL}$ of $0.05 \mathrm{M}$ phosphate buffer $\mathrm{pH}$ 7.0 and $3.9 \mathrm{~mL}$ of distilled water, and then kept in screwcapped containers at $40{ }^{\circ} \mathrm{C}$ in the dark. To $0.1 \mathrm{~mL}$ of this solution were 
added $9.7 \mathrm{~mL}$ of $75 \%$ ethanol and $0.1 \mathrm{~mL}$ of $30 \% \mathrm{w} / \mathrm{v}$ ammonium thiocyanate. Precisely 3 min after the addition of $0.1 \mathrm{~mL}$ of $20 \mathrm{mM}$ ferrous chloride in $3.5 \% \mathrm{v} / \mathrm{v}$ ) hydrochloric acid to the reaction mixture, the absorbance of the resulting red solution was measured at 500 $\mathrm{nm}$, and repeated at $24 \mathrm{~h}$ intervals until the absorbance of the control reached maximum value. Percent inhibition of linoleic acid peroxidation was calculated as in $\mathrm{Eq} 1$.

Inhibition (\%) $\left.=100-\left[A_{s} / A_{c}\right) \times 100\right] \ldots$.

where $A_{s}=$ absorbance increase of the sample and $A_{c}=$ absorbance increase of the control. All tests were run in duplicate, and the mean taken. Vit $\mathrm{C}$ and $\mathrm{BHA}$ were used as positive control.

\section{Hydrogen peroxide scavenging activity}

The ability of the extracts to scavenge hydrogen peroxide was spectrophotometrically [11,14]. A solution of hydrogen peroxide $(40 \mathrm{mM})$ was prepared in phosphate buffer ( $\mathrm{pH}$ 7.4). The extract (0.1-1 $\left.\mathrm{mg} \mathrm{ml}^{-1}\right)$ in distilled water was added to a hydrogen peroxide solution $(0.6 \mathrm{ml}, 40 \mathrm{mM})$. The absorbance of hydrogen peroxide at $230 \mathrm{~nm}$ was determined after 10 min against a blank solution containing phosphate buffer without hydrogen peroxide. The percentage of hydrogen peroxide scavenged by the extracts and standard was calculated as Eq 2.

$\%$ scavenged $\left(\mathrm{H}_{2} \mathrm{O}_{2}\right)=\left(A_{o}-A_{1}\right) / A_{o} \times 100$

where $A_{o}$ is the absorbance of the control and $A_{1}$ the absorbance in the presence of the extract or standard.

\section{Statistical analysis}

Experimental results were expressed as mean \pm SD. The data were analysed by Analysis of Variance and the means separated by Duncan's multiple range test. Data were considered significant at $p<0.05$. The $\mathrm{IC}_{50}$ values were calculated from linear regression analysis.

\section{RESULTS}

\section{Total phenol and flavonoid contents}

Total phenol compounds, reported as gallic acid equivalents, were derived from a standard curve $\left(y=0.0063 x, r^{2}=0.987\right)$. Total phenolic contents of $O$. sintenisii bulbs and aerial parts were $8.4 \pm 0.3$ and $28.9 \pm 1.1$ $\mathrm{mg}$ gallic acid equivalent/g of extract powder, respectively. The total flavonoid contents of $O$. sintenisii bulbs and aerial parts were $5.9 \pm$ 0.2 and $23.5 \pm 1.3 \mathrm{mg}$ quercetin equivalent $/ \mathrm{g}$ of extract powder, respectively, as derived from a standard curve $(y=0.0067 x+0.0132$, $\left.r^{2}=0.999\right)$.

\section{DPPH radical-scavenging activity}

The radical-scavenging activities of the extracts increased with increasing concentration. $\quad \mathrm{IC}_{50}$ for $\mathrm{DPPH}$ radicalscavenging activity was $368 \pm 15$ and $669 \pm$

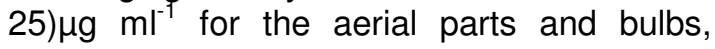
respectively. The $\mathrm{IC}_{50}$ values for ascorbic acid, quercetin and BHA were $5.05 \pm 0.12$, $5.28 \pm 0.43$ and $53.96 \pm 2.13 \mu \mathrm{g} \mathrm{ml}{ }^{-1}$, respectively.

\section{Reducing power}

Fig. 1 shows the dose-response curves for the reducing powers of the extracts. The reducing power of the extracts increased with increase in their concentrations. The extracts exhibited fairly good reducing power at 25 and $800 \mathrm{mg} \mathrm{ml}^{-1}$ but were, however, less than that of vitamin $C(p<0.001)$. Aerial parts showed stronger activity than the bulbs $(p<$ 0.01).

\section{Nitric oxide-scavenging activity}

Table 1 shows the data for scanvening activities. The extract of the aerial parts showed moderately good nitric oxidescavenging activity of between 0.2 and 3.2 $\mathrm{mg} \mathrm{ml}^{-1}$. Inhibition increased with increasing concentration of the extracts. The aerial parts extract showed higher scavenging activity 
with $\mathrm{IC}_{50}$ of $339 \pm\left. 13 \mu \mathrm{g} \mathrm{ml}\right|^{-1}$. The bulbs showed only $22.18 \%$ scavenging activity at $3.2 \mathrm{mg} \mathrm{ml}^{-1}$. IC $\mathrm{C}_{50}$ of quercetin was $20 \pm 0.3 \mu \mathrm{g}$ $\mathrm{ml}^{-1}$.

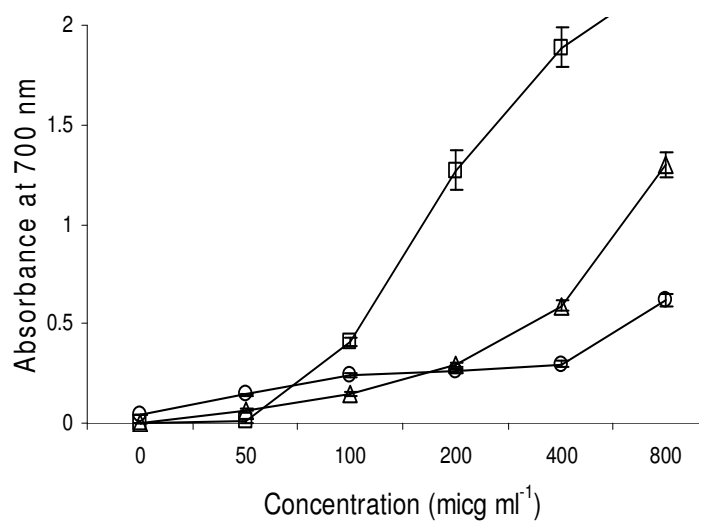

Fig 1: Reducing power of $O$. sintenisii bulbs (o) and aerial parts $(\Delta)$ at flowering stage, and of control (vitamin C) ( $\square$ ).

\section{$\mathrm{Fe}^{2+}$ - chelating ability}

The absorbance of $\mathrm{Fe}^{2+}$-ferrozine complex was decreased in a dose-dependent manner, i.e., activity increased on increasing concentration from 0.2 to $0.8 \mathrm{mg} \mathrm{ml}^{-1}$ (see Table 1). The aerial parts showed greater $\mathrm{Fe}^{2+}$ - chelating activity than the bulbs. $\mathrm{IC}_{50}$ was $340 \pm 14$ for aerial parts and $684 \pm 27 \mu \mathrm{g}$ $\mathrm{ml}^{-1}$ for the bulbs. EDTA (standard) showed very strong activity $\left(\mathrm{IC}_{50}=18 \mu \mathrm{g} \mathrm{ml}^{-1}\right)$.

\section{Peroxidation inhibition}

The plant extracts did not show any activity in peroxidation inhibition test (Table 1). Vitamin $\mathrm{C}$ and $\mathrm{BHA}$, which were used as controls, showed 91 - $98 \%$ inhibition at different incubation times (24 - $96 \mathrm{~h}$ ).

\section{Hydrogen peroxide scavenging}

The extracts scavenged hydrogen peroxide in a concentration-dependent manner (Table 1). Both of them showed very good scavenging activity. $\mathrm{IC}_{50}$ for $\mathrm{H}_{2} \mathrm{O}_{2}$ scavenging was $54.6 \pm$ 1.9 and $294 \pm 11 \mathrm{\mu g} \mathrm{ml}^{-1}$ for the bulbs and aerial parts, respectively while $\mathrm{IC}_{50}$ values for ascorbic acid and quercetin were $21.4 \pm 0.1$ and $52.0 \pm 3.1 \mu \mathrm{g} \mathrm{ml}^{-1}$, respectively (Table 1).

\section{DISCUSSION}

Phenols and polyphenolic compounds, such as flavonoids, are widely found in food products derived from plant sources, and they have been shown to possess significant antioxidant activities [16]. Studies have shown that increasing levels of flavonoids in the diet could reduce the incidence of certain human diseases [10].

$\mathrm{DPPH}$ radical scavenging is a widely used method to evaluate the free radical scavenging ability of various materials [11]. DPPH is a stable nitrogen-centred free radical, the colour of which changes from violet to yellow upon reduction by either the process of hydrogen- or electron- donation.

Table 1: Antioxidant activities of the bulb and aerial parts of $O$. sintenisii at flowering stage

\begin{tabular}{|c|c|c|c|c|}
\hline $\begin{array}{c}\text { Antioxidant } \\
\text { material }\end{array}$ & $\begin{array}{l}\text { DPPH free radical } \\
\text { scavenging, } \\
\text { IC }_{50}\left(\mu \mathrm{g} \mathrm{ml}^{-1}\right)\end{array}$ & $\begin{array}{l}\text { Nitric oxide } \\
\text { scavenging, } \\
\mathrm{IC}_{50}\left(\mu \mathrm{g} \mathrm{\textrm { } \mathrm { I } ^ { - 1 }}\right)\end{array}$ & $\begin{array}{c}\mathrm{H}_{2} \mathrm{O}_{2} \text { scavenging } \\
\text { activity, } \\
\mathrm{IC}_{50}\left(\mu \mathrm{g} \mathrm{ml}^{-1}\right)\end{array}$ & $\begin{array}{c}\mathrm{Fe}^{2+} \text { chelating } \\
\text { ability, } \\
\mathrm{IC}_{50}\left(\mu \mathrm{g} \mathrm{m \textrm {I } ^ { - 1 }}\right)\end{array}$ \\
\hline Aerial parts & $368 \pm 15$ & $339 \pm 13$ & $294 \pm 11$ & $340 \pm 14$ \\
\hline Bulbs & $669 \pm 25$ & $22.2 \%{ }^{\mathrm{a}}$ & $54.6 \pm 1.9$ & $684 \pm 27$ \\
\hline $\mathrm{BHA}$ & $53.96 \pm 2.31$ & & & \\
\hline Vitamin C & $5.05 \pm 0.12$ & - & $21.4 \pm 1.1$ & - \\
\hline EDTA & - & - & - & $18 \pm 1.5$ \\
\hline Quercetin & $5.28 \pm 0.43$ & $20 \pm 0.3$ & $52 \pm 2.6$ & - \\
\hline
\end{tabular}


Substances which are able to perform this reaction can be considered as antioxidants and, therefore, radical scavengers [10]. It was found that the radical-scavenging activities of both extracts increased with increasing concentration. High total phenol and flavonoid contents of aerial parts of plant may be a reason for its higher DPPH-scavenging activity than that of the bulb.

Fe (III) reduction is often used as an indicator of electron- donating activity, which is an important mechanism of phenolic antioxidant action [13]. Although, the reducing power of extracts was less than that of Vit $C(p<0.01)$, the aerial parts showed stronger activity than the bulbs $(p<0.01)$. It was evident that $O$. sintenisii showed reductive potential and could serve as an electron donor for terminating radical chain reaction. It would seem that the higher total phenol and flavonoid contents iof the aerial parts of the plant led to the higher reductive potential of the extract.

The aerial parts extract showed moderately good nitric oxide-scavenging activity of between 0.2 and $3.2 \mathrm{mg} \mathrm{ml}^{-1}$. In addition to reactive oxygen species, nitric oxide is also implicated in inflammation, cancer and other pathological conditions [11]. Consequently, this plant has potentials for counteract the effect of NO formation and, therefore, may be of considerable interest in preventing the ill effects of excessive NO generation in the human body. Furthermore, NO scavenging activity may also help to arrest the chain of reactions initiated by excess generation of NO that are detrimental to human health.

Iron chelators mobilise tissue iron by forming soluble, stable complexes that are then excreted in faeces and/or urine. Chelation therapy reduces iron-related complications in humans and thereby improves quality of life and overall survival in some diseases such as thalassemia major [16]. In addition, brain iron dysregulation and its association with amyloid precursor protein plaque formation are implicated in Alzheimer's disease (AD) pathology and so iron chelation could be considered a rational therapeutic strategy for $A D$ [14]. Foods are often contaminated with transition metal ions which may be introduced by processing methods [10]. Bivalent transition metal ions play an important role as catalysts of oxidative processes, leading to the formation of hydroxyl radicals and hydroperoxide decomposition reactions via Fenton chemistry [14]. These processes can be delayed by iron chelation and deactivation. The transition metal, iron, is capable of generating free radicals from peroxides by Fenton reactions and may be implicated in human cardiovascular disease [18]. Because $\mathrm{Fe}^{2+}$ also has been shown to cause the production of oxyradicals and lipid peroxidation, minimising $\mathrm{Fe}^{2+}$ concentration in Fenton reactions affords protection against oxidative damage. In this assay, both the extracts and EDTA interferred with the formation of ferrous and ferrozine complex, suggesting that the extracts have chelating activity and capture ferrous ion before ferrozine. The absorbance of $\mathrm{Fe}^{2+}$ - ferrozine complex was decreased dose-dependently, i.e., the activity increased on increasing extract concentration from 0.2 to $3.2 \mathrm{mg} \mathrm{ml}^{-1}$.

Metal chelating capacity was significant since the extract reduced the concentration of the catalyzing transition metal in lipid peroxidation [18]. It has been reported that chelating agents are effective as secondary antioxidants because they reduce the redox potential, thereby stabilising the oxidised form of the metal ion [17]. The aerial part extract showed higher $\mathrm{Fe}^{2+}$ - chelating activity than the bulbs but it was not any where as strong as that of EDTA. The higher total phenol and flavonoid contents of the aerial parts might have led to the higher reductive potential of the extract.

Membrane lipids are rich in unsaturated fatty acids that are most susceptible to oxidative processes. Specifically, linoleic acid and arachidonic acid are targets of lipid peroxidation [10,17]. The inhibition of lipid peroxidation by antioxidants is due to their 
free radical-scavenging activities. Superoxide indirectly initiates lipid peroxidation because superoxide anion acts as a precursor of singlet oxygen and hydroxyl radical [2]. Hydroxyl radicals eliminate hydrogen atoms from the membrane lipids, which results in lipid peroxidation. The plant extracts did not show any peroxidation inhibition activity probably due to other compounds that might be present in the plant that exert lipid peroxidation activity.

Scavenging of $\mathrm{H}_{2} \mathrm{O}_{2}$ by the extracts may be attributed to their phenolics, which can donate electrons to $\mathrm{H}_{2} \mathrm{O}_{2}$, thus neutralising it to water. The extracts were capable of scavenging hydrogen peroxide in a concentration-dependent manner and they both showed very good scavenging activity. Although hydrogen peroxide itself is not very reactive, it can sometimes cause cytotoxicity by giving rise to hydroxyl radicals in the cell. Thus, removing $\mathrm{H}_{2} \mathrm{O}_{2}$ is very important in food processes [11].

\section{CONCLUSION}

O. sintenisii aerial parts (at flowering stage) and bulbs methanol extracts exhibited good but varying levels of antioxidant activity in nearly all the models studied. Overall, probably due to the higher total phenol and flavonoid contents of the aerial parts, this part showed higher antioxidant activity than the bulbs. Isolation of the individual compounds of the extracts, investigation of their in vivo antioxidant activities and the elucidation of their antioxidant mechanisms are required to confirm the findings of this study.

\section{ACKNOWLEDGEMENT}

This research was partially supported by a grant from the Research Council of Mazandaran University of Medical Sciences, Sari, Iran. This paper is dedicated to Seyed Maryam Nabavi.

\section{REFERENCES}

1. Nehir EIS, Karakaya S. Radical scavenging and ironchelating activities of some greens used as traditional dishes in Mediterranean diet. Int $\mathrm{J}$ Food Sci Nutr 2004; 55(1): 67 -74.

2. Nabavi SM, Ebrahimzadeh MA, Nabavi SF, Hamidinia A. Bekhradnia AR. Determination of antioxidant activity, phenol and flavonoids content of Parrotia persica Mey. Pharmacologyonline 2008; 2: 560-567.

3. Nazifi E, Delazar A, Movafeghi A, Hemmati S, Nazemiyeh H, Nahar L, Sarker SD. GC-MS analysis of the dichloromethane extract of the bulbs of Ornithogalum cuspidatum Bert. (Family: Liliaceae) from Iran Rec Nat Prod 2008; 2,3: 94-99.

4. Komissarenko NF. Ornithogalin - a cardenolide Glycoside from Ornithogalum magnum. J Nat Prod 1971;1: 38-40.

5. Bai JF, Liu ZQ, Wang SM, Song FR, Liu SY. Isolation and structure identification of novel monoterpene lactone from Ornithogalum caudatum Ait. Chem J Chinese-Universities 2005; 26: 1817-1819.

6. Tang YP, Yu B, Hu J, Wu T, Hui HZ. Three new homoisoflavanone glycosides from the bulbs of Ornithogalum caudatum. J Nat Prod 2002; 65: 218-220.

7. Kuroda M, Mimaki Y, Yokosuka A, Hasegawa F, Sashida Y. Cholestane Glycosides from the bulbs of Ornithogalum thyrsoides and their cytotoxic activity against HL-60 Leukemia Cells. J Nat Prod 2002; 65(10): 1417 -1423.

8. Ebrahimzadeh MA, Pourmorad F, Hafezi $S$. Antioxidant activities of Iranian Corn Silk. Turk J Biol 2008; 32: 43-49.

9. Ebrahimzadeh MA, Bahramian F. Antioxidant activity of Crataegus pentagina subsp . elbursis Fruits extracts used in traditional medicine in Iran. Pak J Biol Sci 2009; 12(5): 413-419.

10. Dehpour AA, Ebrahimzadeh MA, Nabavi SF, Nabavi SM. Antioxidant activity of methanol extract of Ferula assafoetida and its essential oil composition. Grasas Aceites 2009; 60(4): 405412.

11. Ebrahimzadeh MA, Nabavi SF, Nabavi SM. Antioxidant activities of methanol extract of sambucus ebulus L. flower. Pak J Biol Sci 2009; 12(5): 447-450.

12. Nabavi SM, Ebrahimzadeh MA, Nabavi SF, Jafari M. Free radical scavenging activity and antioxidant capacity of Eryngium caucasicum TRAUTV and Froriepia subpinnata. Pharmacologyonline 2008; 3: 19-25.

13. Nabavi SM, Ebrahimzadeh MA, Nabavi SF, Fazelian $M$, Eslami B. In vitro antioxidant and free radical scavenging activity of Diospyros lotus and Pyrus boissieriana growing in Iran. Pharmacog Mag 2009; 4(18):123-127.

14. Ebrahimzadeh MA, Nabavi SM, Nabavi SF, Eslami $B$. Free radical scavenging ability of 
Ebrahimzadeh et al

methanolic extract of Hyoscyamus squarrosus leaves. Pharmacologyonline 2009; 2: 796-802.

15. Nabavi SM, Ebrahimzadeh MA, Nabavi SF, Bahramian F. In vitro Antioxidant activity of Phytolacca Americana Berries. Pharmacologyonline 2009; 1: 81-88.

16. Ebrahimzadeh MA, Nabavi SM, Nabavi SF. Correlation between the in vitro iron chelating activity and poly phenol and flavonoid contents of some medicinal plants. Pak J Biol Sci 2009; 12(12): 934-938.
17. Ebrahimzadeh MA, Nabavi SM, Nabavi SF, Eslami B. Antioxidant activity of aqueous extract of Pyrus boissieriana fruit. Pharmacologyonline 2009; 1: 1318-1323.

18. Ebrahimzadeh MA, Pourmorad F, Bekhradnia AR. Iron chelating activity screening, phenol and flavonoid content of some medicinal plants from Iran. Afr J Biotech 2008; 7 (18): 31883192. 